\title{
Small molecule mixture analysis by heteronuclear NMR under spin diffusion conditions in the viscous DMSO-water solvent
}

\author{
Pedro Lameiras ${ }^{*},{ }^{[a]}$ Solène Patis,${ }^{[a]}$ Jouda Jakhlal, ${ }^{[a]}$ Stéphanie Castex,${ }^{[a]}$ Pascale Clivio ${ }^{\left[{ }^{[a]}\right.}$ and Jean- \\ Marc Nuzillard ${ }^{*[a]}$
}

\begin{abstract}
Spin diffusion in NMR occurs for small and medium-sized molecules when their tumbling rate reduces in solution so that magnetization exchange by longitudinal cross relaxation becomes highly efficient. Composite DMSO-water viscous solvents were used for the first time to access the individual NMR spectra of mixture components in spin diffusion conditions. The easy handling and high dissolution power of $\left[\mathrm{D}_{6}\right] \mathrm{DMSO} / \mathrm{H}_{2} \mathrm{O}$ offers a wide range of potential applications for polar and moderately apolar mixture analysis. In addition to 2D ${ }^{1} \mathrm{H}-{ }^{1} \mathrm{H}$ NOESY and ${ }^{1} \mathrm{H}-{ }^{13} \mathrm{C}$ HSQC-NOESY, ${ }^{1} \mathrm{H}-{ }^{15} \mathrm{~N}$ HSQC-NOESY, 1D and 2D ${ }^{1} \mathrm{H}^{19} \mathrm{~F}$ HOESY experiments were set up to offer new ways to individualize molecules within a mixture. This article reports the analysis of a polar mixture of four dipeptides dissolved in $\left[\mathrm{D}_{6}\right] \mathrm{DMSO} / \mathrm{H}_{2} \mathrm{O}(7: 3, \mathrm{v} / \mathrm{v})$ and of a medium polarity fluorinated dinucleotide dissolved in $\left[\mathrm{D}_{6}\right] \mathrm{DMSO} / \mathrm{H}_{2} \mathrm{O}(8: 2, \mathrm{v} / \mathrm{v})$ by means of spin diffusion in NOESY, HOESY, and HSQC-NOESY experiments.
\end{abstract}

\section{Introduction}

Mixture analysis by NMR is a topic that is nearly as old as NMR itself and for which only few solutions have been proposed, such as LC-NMR hyphenation, diffusion ordered experiments (DOSY), multi-quantum NMR spectroscopy combined or not with broadband homonuclear decoupling, sparse sampling and pure shift data acquisition. ${ }^{[1]}$

The recent use of viscous solvents has provided an interesting approach to the study of mixtures by lowering the molecular tumbling rate in solution. ${ }^{[2]}$ As a result, the molecules display a negative nOe regime and their resonances can be grouped according to their ability to exchange magnetization through intramolecular spin diffusion. The 2D ${ }^{1} \mathrm{H}-{ }^{1} \mathrm{H}$ NOESY spectrum of a mixture shows correlations between all the ${ }^{1} \mathrm{H}$ resonances of each analyte when recorded in spin diffusion conditions, thus giving access to the individual ${ }^{1} \mathrm{H}$ NMR spectra of the mixture components.

Earlier works on viscous solvents showed that polymeric fluorinated oils were unsuitable for the dissolution of highly polar molecules while glycerol was not adapted to the study of low polarity molecules. ${ }^{[2 a, e, f, 3]}$ The present work introduces viscous

[a] Dr. P. Lameiras, Ms. S. Patis, Dr. J. Jakhlal, Dr. S. Castex, Dr. P. Clivio, Dr. J-M. Nuzillard

Université de Reims Champagne-Ardenne, Institut de Chimie Moléculaire de Reims, CNRS UMR 7312, SFR CAP-Santé BP 1039, 51687 Reims Cedex 02 (France)

pedro.lameiras@univ-reims.fr

jm.nuzillard@univ-reims.fr

Supporting information for this article is given via a link at the end of the document. solvent blends made of $\left[\mathrm{D}_{6}\right] \mathrm{DMSO}$ and water that are potentially adapted to the study of polar and moderately apolar compounds. It focusses on the assessment of $\left[\mathrm{D}_{6}\right] \mathrm{DMSO} / \mathrm{H}_{2} \mathrm{O}$ in the individualization of mixed Leu-Val, Leu-Tyr, Gly-Tyr and Ala-Tyr dipeptides and in the study of a synthetic difluorinated dinucleotide, $2^{\prime} \mathrm{ar} T p_{3^{\prime} \mathrm{ar}} \mathrm{T}$ (Chemical structure in Figure $4 \mathrm{~b}$ and Figure S-6). The synthesis of this molecule has not been reported to date but was carried out according to already reported methods. ${ }^{[4]}$ The main advantage of $\left[D_{6}\right] D M S O /$ water blends as NMR solvents is their low viscosity at ambient temperature ${ }^{[5]}$ so that samples may be prepared and transferred into NMR sample tube without any difficulty, contrarily to the solvents that are based on glycerol or glycerol carbonate. Adding $\mathrm{H}_{2} \mathrm{O}$ to $\left[\mathrm{D}_{6}\right] \mathrm{DMSO}$ also opens the way of working at or below room temperature, which is especially appropriate for thermally unstable compounds. The freezing point of the solvent blend decreases considerably with the amount of added $\mathrm{H}_{2} \mathrm{O}$. ${ }^{[6]}$ For example, $30 \%$ of $\mathrm{H}_{2} \mathrm{O}(\mathrm{v} / \mathrm{v})$ sets the solvent freezing point close to $228 \mathrm{~K}$. Spin diffusion may occur on a wide range of temperatures, from $228 \mathrm{~K}$ to room temperature and even higher. The large amount of $\left[D_{6}\right] \mathrm{DMSO}$ makes also possible to run spectrometer tools such as the automatic field locking and shimming as for usual solvents. Finally, the residual proton resonance of water is easily eliminated with usual water suppression methods such as presaturation or excitation sculpting. ${ }^{[7]}$

Adjusting the amount of $\mathrm{H}_{2} \mathrm{O}$ (or $\mathrm{D}_{2} \mathrm{O}$ ) in $\left[\mathrm{D}_{6}\right] \mathrm{DMSO}$ from a minimum value of $10 \%$ to $30 \%(\mathrm{v} / \mathrm{v})$, or even more, makes possible to modulate the spin diffusion efficiency and therefore to achieve the individualization of a wide range of polar and moderately apolar compounds within mixtures. $\left[\mathrm{D}_{6}\right] \mathrm{DMSO} / \mathrm{H}_{2} \mathrm{O}$ will be considered for the study of biological active compounds in which labile protons such as amide protons must not be exchanged with the $D_{2} \mathrm{O}$ deuterium nuclei. $\left[D_{6}\right] \mathrm{DMSO} / \mathrm{D}_{2} \mathrm{O}$ will be favored for organic compounds in which labile protons are not essential to structure elucidation. The medium-sized molecules only will require a low amount of $\mathrm{H}_{2} \mathrm{O}\left(\right.$ or $\mathrm{D}_{2} \mathrm{O}$ ) in [D $\left.\mathrm{D}_{6}\right] \mathrm{DMSO}$ while smaller molecules will require more $\mathrm{H}_{2} \mathrm{O}$ (or $\mathrm{D}_{2} \mathrm{O}$ ), until $30 \%(\mathrm{v})$, for driving spin diffusion under temperature control from $298 \mathrm{~K}$ to $238 \mathrm{~K}$. The criterion for optimal temperature selection is a compromise between overall spectral resolution and intensity of NOESY (or HOESY) cross peaks between nuclei that are not close enough to show a nOe signal in a low viscosity medium. A temperature reduction enhances spin diffusion but also reduces peak height through line broadening caused by a more efficient transverse relaxation process. Sample cooling is therefore required if the NOESY spectrum shows positive nOe responses (diagonal and offdiagonal peaks of opposite signs).

Depending on the complexity of the mixtures, the analysis of ${ }^{1} \mathrm{H}$ NMR spectra may become intractable due to the overlapping 
of ${ }^{1} \mathrm{H}$ resonances. A common remedy to this difficulty consists in the spreading of the spectroscopic information along a second axis that encodes chemical shifts of nuclei other than ${ }^{1} \mathrm{H}$. Previous studies have shown that $2 \mathrm{D}{ }^{1} \mathrm{H}-{ }^{13} \mathrm{C}$ HSQC-NOESY spectra in spin diffusion conditions simultaneously provides ${ }^{1} \mathrm{H}$ and ${ }^{13} \mathrm{C}$ chemical shift lists for the mixture components. ${ }^{[2]}$ The straightforward but original extension to $2 \mathrm{D}{ }^{1} \mathrm{H}-{ }^{15} \mathrm{~N}$ HSQCNOESY is illustrated hereafter. Fluorine-19 is a nucleus with $100 \%$ natural abundance and with a high magnetogyric ratio, so that it may be involved like the ${ }^{1} \mathrm{H}$ nucleus in spin diffusion experiments. This approach to mixture analysis is original and is exemplified by $1 \mathrm{D}$ and $2 \mathrm{D}{ }^{1} \mathrm{H}-{ }^{19} \mathrm{~F}$ HOESY spectra.

\section{Results and Discussion}

Leu-Val, Leu-Tyr, Gly-Tyr and Ala-Tyr mixture in $\left[\mathrm{D}_{6}\right] \mathrm{DMSO} / \mathrm{H}_{2} \mathrm{O}(7: 3, \mathrm{v} / \mathrm{v})$

These four dipeptides do not reveal any differentiation of their translational diffusion behavior in water, due to their similar molecular mass and shape (Figure S-1 from Supporting Information (SI)). ${ }^{[2 h]}$ Considering homo- and heteronuclear spin diffusion is a pertinent alternative to DOSY for the effective discrimination of their NMR spectra.

The optimal temperature conditions for setting up heteronuclear NMR experiments in spin diffusion regime have been experimentally determined by means of the basic $2 \mathrm{D}{ }^{1} \mathrm{H}-{ }^{1} \mathrm{H}$ NOESY experiment with water suppression by excitation sculpting. ${ }^{[7]}$ Figure S-2 (SI) reports the evolution of the NOESY correlations of the amide protons in the dipeptide test mixture upon sample temperature modification. The spectra reveal the expected intra-molecular correlations but also show some magnetization transfer between the dipeptides and HOD whose intensity is related to temperature. Ambient and lower temperatures ( $288 \mathrm{~K}, 278 \mathrm{~K}, 268 \mathrm{~K}, 258 \mathrm{~K}$ and $248 \mathrm{~K}$ ) have been tested, $268 \mathrm{~K}$ being the optimal temperature at which the NOESY spectrum of the dipeptide test mixture shows correlations from the amide proton resonance of each dipeptide to all the proton resonances of the same dipeptide, without significant signal broadening. The four peptides slowly reorient in the binary solvent and thus reveal a negative nOe regime (black correlation peaks in the NOESY spectrum, Figure 1a and full NOESY spectrum in Figure S-3). As a result, the individualization of the peptides within their mixture is readily obtained. Conversely, when the spectrum is recorded in water at $298 \mathrm{~K}$, the four dipeptides rapidly reorient and present a positive nOe regime (blue correlation peaks in the usual NOESY spectrum), thus preventing spin diffusion to be observed. As a consequence, the $\mathrm{NH}$ signals in Leu-Tyr, Gly-Tyr and Ala-Tyr only correlate with one of the two tyrosine $\mathrm{H} \beta$ protons and with none of the aromatic $\mathrm{H} \varepsilon$ protons (Figure $1 \mathrm{~b}$ and full NOESY spectrum in Figure S-4). The individualization of the four dipeptides in water would require the simultaneous use of $\mathrm{J}$ coupling and dipolar-coupling based ${ }^{1} \mathrm{H}$ multidimensional correlation NMR experiments such as COSY/TOCSY and NOESY, according to the usual strategy for peptide resonance assignment. ${ }^{[8]}$
For analytical purposes, it appears that detecting only the resonances of interest during signal acquisition may provide supplementary structural information by avoiding proton resonance overlapping especially for complex mixtures. Selectively exciting one appropriate set of proton resonances by means of 1D selective NOESY experiments illustrates this approach.

In the 1D selective NOESY experiment, a single spin is excited, its magnetization is further flipped to bring it to the $-z$ axis where it can spread by spin diffusion along the molecular proton network. The main difficulty here is to avoid the reintroduction of the water signal at detection time. ${ }^{[9]}$ The 1D selective NOESY pulse sequence in Figure $2 f$ starts with a multiplet selective excitation block. ${ }^{[9-10]}$ Two wideband inversion pulses have been inserted during the mixing time. Their position has been adjusted in order to minimize the amount of resurrected HOD magnetization that arises by longitudinal relaxation.

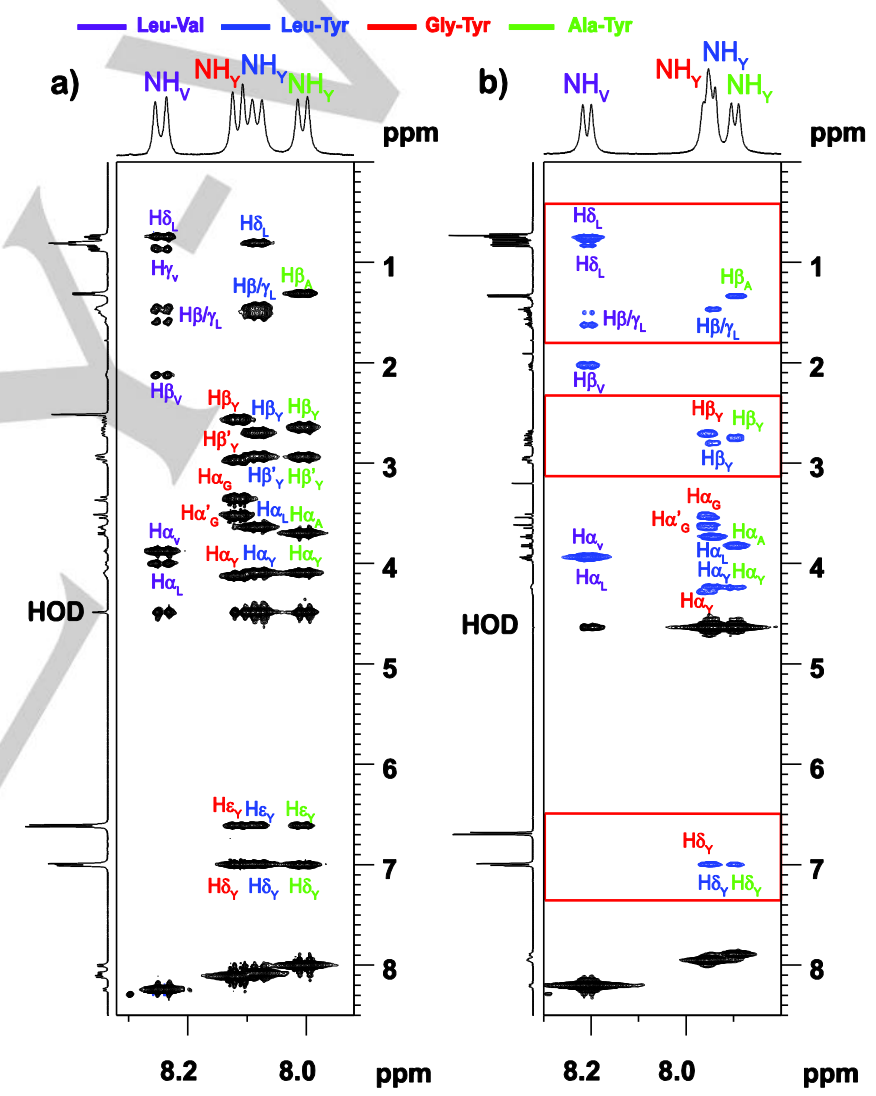

Figure 1. Amide proton region of 2D NOESY spectra of dipeptide test mixture (10 mM), mixing time $\left(t_{m}\right)=1 \mathrm{~s}$, at $500 \mathrm{MHz}\left({ }^{1} \mathrm{H}\right)$, a) dissolved in $\left[\mathrm{D}_{6}\right] \mathrm{DMSO} / \mathrm{H}_{2} \mathrm{O}(7: 3, v / \mathrm{v})$, at $\left.268 \mathrm{~K}, \mathrm{~b}\right)$ dissolved in $\mathrm{H}_{2} \mathrm{O} / \mathrm{D}_{2} \mathrm{O}(9: 1, \mathrm{v} / \mathrm{v})$, at 298 $\mathrm{K}$. The red frames correspond to spectral regions of interest in which water as solvent has a major effect on the number and sign of observable NOESY cross peaks.

The 1D selective NOESY spectra in Figure 2 show that all dipeptides are differentiated by spin diffusion in $\left[\mathrm{D}_{6}\right] \mathrm{DMSO} / \mathrm{H}_{2} \mathrm{O}$, using an appropriate set of selectively excited proton resonances. Indeed, the selective excitation of the $\mathrm{NH}$ amide proton at $8.25 \mathrm{ppm}$ reveals a magnetization exchange exclusively with the protons of the Leu-Val dipeptide because the tyrosine $\mathrm{H} \delta / \mathrm{H} \varepsilon$ proton resonances do not appear in the $1 \mathrm{D}$ 
NOESY spectrum (Figure 2a). The selective excitation of the side chain $\mathrm{H} \delta$ and $\mathrm{H} \gamma$ protons (between 0.65 and 0.95 ppm) shows a magnetization exchange with all protons of the two LeuVal and Leu-Tyr dipeptides (Figure 2b). By comparison with the 1D NOESY spectra in Figures $2 a$ and $2 b$, a complete proton assignment of Leu-Tyr is made possible. The selective excitation of the aromatic $\mathrm{H} \delta$ protons of Leu-Tyr, Gly-Tyr and Ala-Tyr reveals all the proton resonances of Leu-Tyr, Gly-Tyr and AlaTyr (Figure $2 \mathrm{c}$ ). $\mathrm{CH}_{3} \beta$ protons at $1.31 \mathrm{ppm}$ is selectively excited in order to differentiate all proton resonances from Ala-Tyr and Gly-Tyr (Figure 2d). Figure 2d clearly shows the transfer of the $\mathrm{CH}_{3} \beta$ magnetization over all protons of Ala-Tyr. The individual ${ }^{1} \mathrm{H}$ spectrum of Gly-Tyr is obtained after selectively exciting the $\mathrm{Ha}$ proton at $3.35 \mathrm{ppm}$ (Figure 2e).

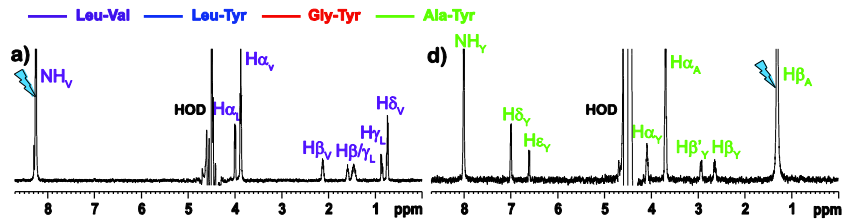

b)
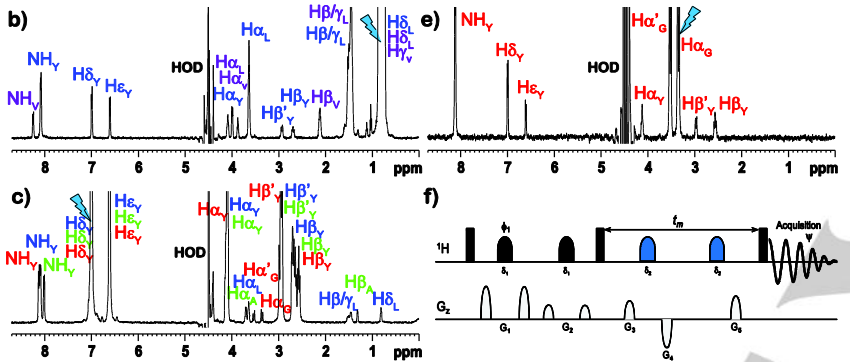

Figure 2. Multiplet selective excitation 1D ${ }^{1} \mathrm{H}$ NOESY spectra of the dipeptide test mixture $(10 \mathrm{mM})$ dissolved in $\left[\mathrm{D}_{6}\right] \mathrm{DMSO} / \mathrm{H}_{2} \mathrm{O}(7: 3, \mathrm{v} / \mathrm{v})(\mathrm{a}, \mathrm{b}, \mathrm{c}, \mathrm{d}, \mathrm{e}, 268$ $\mathrm{K}), t_{m}=1 \mathrm{~s}$, at $\left.500 \mathrm{MHz}\left({ }^{1} \mathrm{H}\right) . \mathrm{f}\right)$ Pulse sequence: $\varphi 1=\mathrm{x}, \mathrm{y},-\mathrm{x},-\mathrm{y}, \psi=\mathrm{x},-\mathrm{x}$. The initial selective inversion pulses excite: a) the $\mathrm{NH}_{V}(L V)$ proton resonance; b) the $\mathrm{H} \delta_{\mathrm{L}}(\mathrm{LY}) / \mathrm{H} \delta_{\mathrm{L}}(\mathrm{LV}) / \mathrm{HYV}_{\mathrm{V}}(\mathrm{LV})$ proton resonances; $\left.\mathrm{c}\right)$ the $\mathrm{H} \delta_{Y}(\mathrm{LY}) / \mathrm{H} \delta_{Y}(\mathrm{GY}) / \mathrm{H} \delta_{Y}(\mathrm{AY})$ proton resonances; d) the $\mathrm{H} \beta_{\mathrm{A}}(\mathrm{AY})$ proton resonances; e) the $\mathrm{Ha}_{Y}(\mathrm{GY})$ proton resonance.

The selective excitation of isolated proton resonances enables the individualization of each compound within the mixture by taking benefit from spin diffusion. However, it may happen in other complex mixtures that a component of interest does not present resolved proton resonances due to strong spectral overlap. In such cases, the larger chemical shift dispersion of ${ }^{13} \mathrm{C}$ and ${ }^{15} \mathrm{~N}$ nuclei may prove to be helpful. By coupling the HSQC and NOESY experiments, a complete proton spectrum should be obtained for a molecule starting only from a single carbon or nitrogen resonance.

The 2D ${ }^{1} \mathrm{H}^{13} \mathrm{C}$ and ${ }^{1} \mathrm{H}-{ }^{15} \mathrm{~N}$ HSQC-NOESY spectra of the dipeptide test mixture were recorded at $268 \mathrm{~K}$ in $\left[\mathrm{D}_{6}\right] \mathrm{DMSO} / \mathrm{H}_{2} \mathrm{O}$ $(7: 3, v / v)$ (Figure S-5 and Figure 3). Under these conditions, all protons of each dipeptide of the mixture are able to correlate with all other protons and protonated carbons or protonated nitrogen by spin diffusion. An appropriate selection of horizontal slices through carbon resonances at 31.63 and $41.31 \mathrm{ppm}$ (LeuVal), $38.38 \mathrm{ppm}$ (Gly-Tyr), $50.0 \mathrm{ppm}$ (Ala-Tyr) and $52.89 \mathrm{ppm}$ (Leu-Tyr), enables the extraction of the four complete proton spectra respectively corresponding to Leu-Val, Gly-Tyr, Ala-Tyr and Leu-Tyr. These four spectra have been compared to the conventional 1D ${ }_{1} \mathrm{H}$ spectra (Figures S-5b, b', S-5d, d', S-5e, e' and S-5c, c') and they logically present similar peak patterns. In the same way, an appropriate selection of four horizontal slices through nitrogen resonances at 125.33 (Leu-Val), 125.19 (LeuTyr), 124.26 (Gly-Tyr), and 123.29 ppm (Ala-Tyr) makes possible to produce four complete $1 \mathrm{H}$ spectra respectively corresponding to Leu-Val, Leu-Tyr, Gly-Tyr and Ala-Tyr. These four spectra present resonance patterns similar to those of the conventional 1D ${ }^{1} \mathrm{H}$ spectra as well (Figures 3b, b', 3c, c', 3d, d' and $\left.3 e, e^{\prime}\right)$. Interestingly, another approach is possible to individualize the compounds of the mixture by considering appropriate vertical slices from the $2 \mathrm{D}{ }^{1} \mathrm{H}^{13} \mathrm{C}$ HSQC-NOESY (Figure S-5). In this case, the resulting spectra should reveal all the protonated carbons of the four dipeptides in the mixture. Figure S-5 (f, f', g, g', h, h' and i, i') compares the DEPT135 spectrum of respectively Leu-Val, Leu-Tyr, Gly-Tyr, and Ala-Tyr to the protonated carbon spectrum obtained by extracting the column of amide protons at $8.26,8.10,8.14$ and $8.02 \mathrm{ppm}$. The ability to extract all the protonated carbon chemical shifts for an individual component in a mixture may prove to be a very useful tool in the structure assignment of molecules within mixtures.

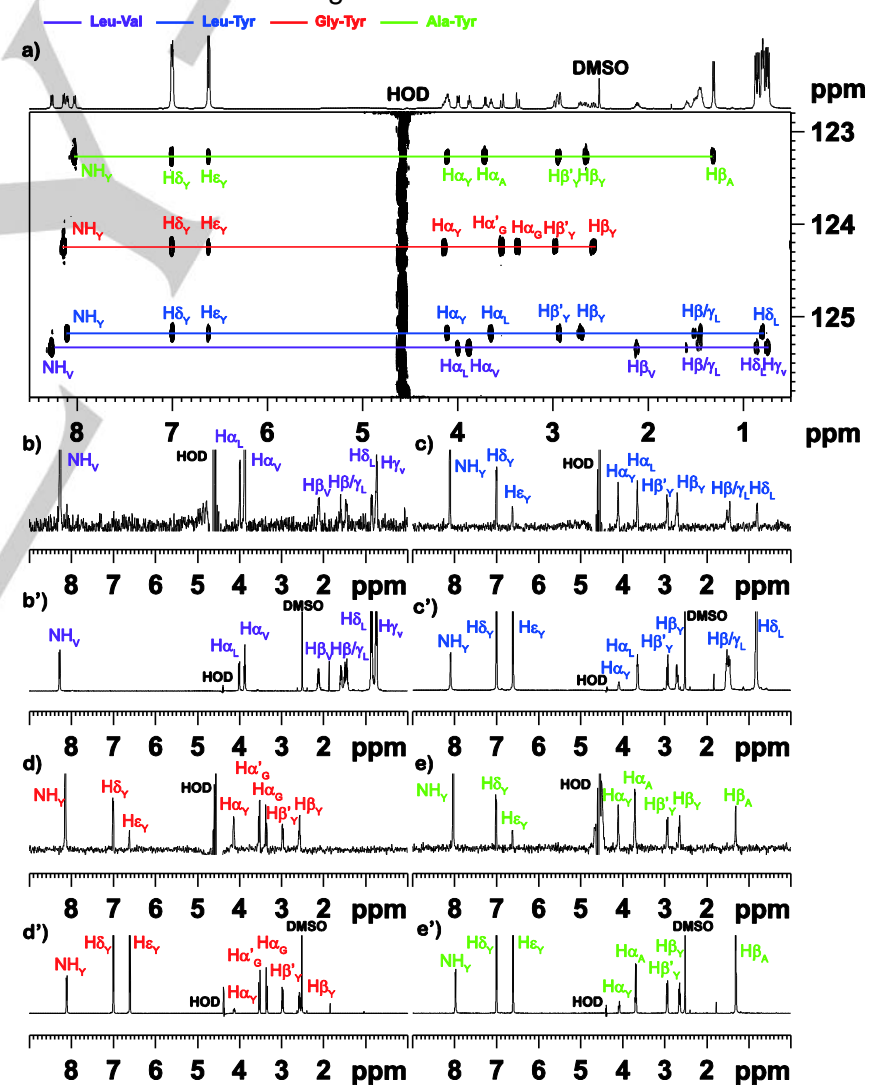

Figure 3. a) $2 \mathrm{D}{ }^{1} \mathrm{H}-{ }^{15} \mathrm{~N}$ HSQC-NOESY spectrum of the dipeptide test mixture $(20 \mathrm{mM})$ dissolved in $\left[\mathrm{D}_{6}\right] \mathrm{DMSO} / \mathrm{H}_{2} \mathrm{O}(7: 3, \mathrm{v} / \mathrm{v})$, at $268 \mathrm{~K}, t_{m}=1 \mathrm{~s}$, at $600 \mathrm{MHz}$ $\left({ }^{1} \mathrm{H}\right)$. Comparison of four ${ }^{1} \mathrm{H}$ horizontal slices extracted from the $2 \mathrm{D}{ }^{1} \mathrm{H}-{ }^{15} \mathrm{~N}$ HSQC-NOESY at 125.33 (b, b', Leu-Val, purple row), 125.19 (c, c', Leu-Tyr, blue row), 124.26 (d, d', Gly-Tyr, red row), and 123.29 ppm (e, e', Ala-Tyr, green row) with the conventional 1D proton spectra of each pure dipeptide dissolved $(20 \mathrm{mM})$ in $\left[\mathrm{D}_{6}\right] \mathrm{DMSO} / \mathrm{H}_{2} \mathrm{O}(7: 3, \mathrm{v} / \mathrm{v})$, at $268 \mathrm{~K}$, at $600 \mathrm{MHz}\left({ }^{1} \mathrm{H}\right)$. 
${ }^{\prime}{ }^{\prime}{ }^{\prime} T p_{3^{\prime}} \mathrm{aF} T$ in $\left[\mathrm{D}_{6}\right] \mathrm{DMSO} / \mathrm{H}_{2} \mathrm{O}(8: 2, \mathrm{v} / \mathrm{v})$

The simplification of mixture analysis by means of heteronuclear chemical shift resonance labelling was extended to ${ }^{19} \mathrm{~F}$ NMR spectroscopy. Fluorine is a chemical element that is rarely present in natural organic compound but whose introduction in synthetic molecules has offered a wide range of original molecular properties, especially in the fields of material sciences and of therapeutic agents. The wider chemical shift range of ${ }^{19} \mathrm{~F}$ compared to ${ }^{1} \mathrm{H}$ nuclei should facilitate the individualization of fluorinated molecules within mixtures. ${ }^{[11]}$

Spin diffusion in the previously reported heteronuclear NMR experiments only concerns the ${ }^{1} \mathrm{H}$ nuclei of the molecules. Dealing with ${ }^{19} \mathrm{~F}$ NMR, this nucleus can be integrated in the spin network in which magnetization is transferred by cross relaxation. This approach was considered as potentially successful considering that i) fluorine is monovalent and used in molecules as substitute of hydrogen, ii) its natural abundance is $100 \%$, iii) cross relaxation rates are proportional to the product of the squares of the magnetogyric ratios $y$ of the concerned nuclei and iv) $\mathrm{Y}\left({ }^{19} \mathrm{~F}\right) / \mathrm{Y}\left({ }^{1} \mathrm{H}\right)$ is close to one $(0.941$, more precisely). This opens the way to the observation of ${ }^{1} \mathrm{H}-{ }^{19} \mathrm{~F}$ spin diffusion through the HOESY experiment. A synthetic difluorinated dinucleotide, $2^{\prime} \alpha T^{\prime} p_{3^{\prime} \alpha F} T$ (Figure $4 b$ and Figure S-6) was chosen in order to illustrate this approach. Spectra were recorded in $\left[\mathrm{D}_{6}\right] \mathrm{DMSO} / \mathrm{H}_{2} \mathrm{O}$ instead of $\left[\mathrm{D}_{6}\right] \mathrm{DMSO} / \mathrm{D}_{2} \mathrm{O}$ in order to avoid the $\mathrm{NH}$ proton exchange with the deuterium from $\mathrm{D}_{2} \mathrm{O}$.

The first step has been to determine the temperature that provides the best compromise between spin diffusion and spectral resolution. Figure S-7 shows the superposition of $2 \mathrm{D}$ ${ }^{1} \mathrm{H}-{ }^{1} \mathrm{H}$ NOESY and ${ }^{1} \mathrm{H}-{ }^{19} \mathrm{~F}$ HOESY spectra from $268 \mathrm{~K}$ to $238 \mathrm{~K}$ with water suppression using excitation sculpting. ${ }^{[7]} \mathrm{A}$ full magnetization exchange is clearly visible at $238 \mathrm{~K}$ over all the ${ }^{\prime} \mathrm{aFF} \mathrm{Tp}_{\mathrm{3}^{\prime} \mathrm{\alpha F}} \mathrm{T}^{1} \mathrm{H}$ and ${ }^{19} \mathrm{~F}$ nuclei (Figure 4). For instance, the $\mathrm{NH}$ proton resonances at 11.57 and $11.65 \mathrm{ppm}$ are able to propagate their magnetization toward the methyl resonances of the other nucleotide ring respectively resonating at 1.69 and $1.67 \mathrm{ppm}$, and vice versa. Each fluorine resonance respectively at -172.17 and $-200.31 \mathrm{ppm}$ is correlated with all the proton resonances of the molecule (Figure $4 \mathrm{~b}$ ).

By extracting appropriate set of rows and columns, the individual ${ }^{1} \mathrm{H}$ and ${ }^{19} \mathrm{~F}$ spectra of the ${ }^{\prime} \mathrm{aF}^{T} \mathrm{~T}_{3^{\prime} \mathrm{\alpha F}} \mathrm{T}$ molecule are easily obtained. Figure 4 (c, c', $d$ and $d^{\prime}$ ) displays the comparison between the row and the column extracted at 11.65 ppm (NH proton) respectively from $2 \mathrm{D}{ }^{1} \mathrm{H}-{ }^{1} \mathrm{H}$ NOESY and ${ }^{1} \mathrm{H}-{ }^{19} \mathrm{~F}$ HOESY spectra with the conventional $1 \mathrm{D}{ }^{1} \mathrm{H}$ and ${ }^{19} \mathrm{~F}$ spectra. As expected, the extracted spectra are similar to the conventional 1D ${ }^{1} \mathrm{H}$ and ${ }^{19} \mathrm{~F}$ spectra. In the study of mixtures of fluorinated compounds, structure elucidation may turn out challenging due to ${ }^{1} \mathrm{H}$ resonance overlapping. Selectively exciting a single appropriate ${ }^{19} \mathrm{~F}$ resonance should solve this issue. Figure 5 shows how each selectively excited ${ }^{19} \mathrm{~F}$ nucleus at -172.19 and $200.3 \mathrm{ppm}$ is able to transfer its magnetization over all the protons of the molecule. For this purpose, a dedicated NMR pulse sequence composed of a double pulse field gradient spin echo block followed by a 1D HOESY block was successfully implemented for the first time (Figure $5 \mathrm{c}$ ). In the other way, the selective excitation of a ${ }^{1} \mathrm{H}$ resonance reveals the chemical shifts of the ${ }^{19} \mathrm{~F}$ nuclei of the corresponding molecule. In our example, dealing with one or the other $\mathrm{NH}$ proton resonance at 11.57 or $11.65 \mathrm{ppm}$ leads to the ${ }^{19} \mathrm{~F}$ spectrum of the sample (Figure S-8).

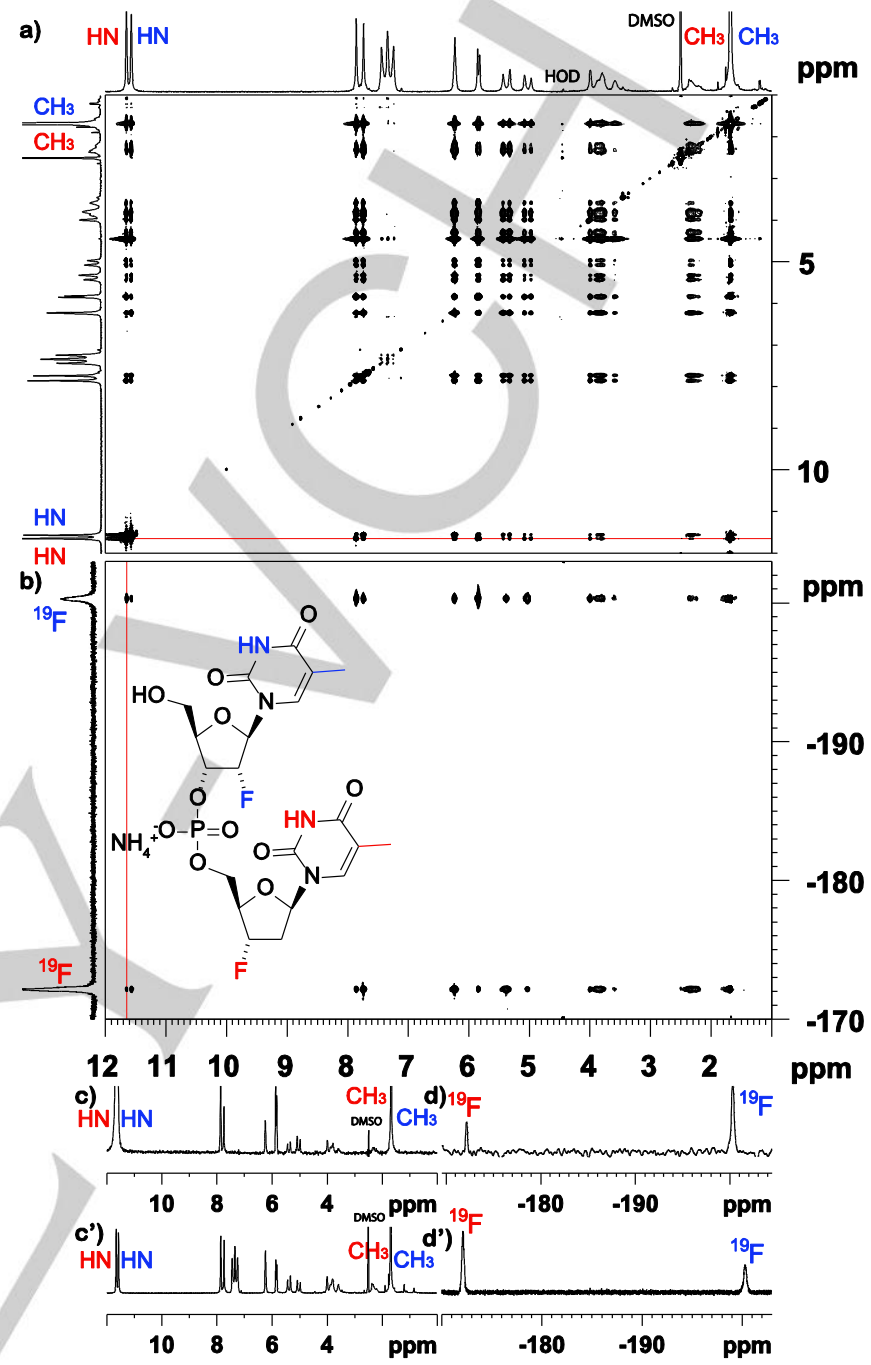

Figure 4. $2 \mathrm{D}{ }^{1} \mathrm{H}-{ }^{1} \mathrm{H}$ NOESY and ${ }^{1} \mathrm{H}^{-19} \mathrm{~F}$ HOESY spectra of ${ }_{2^{\prime} \mathrm{aF}} \mathrm{Tp}_{3^{\prime} \mathrm{aF}} \mathrm{T}(20 \mathrm{mM})$ dissolved in $\left[\mathrm{D}_{6}\right] \mathrm{DMSO} / \mathrm{H}_{2} \mathrm{O}(8: 2, \mathrm{v} / \mathrm{v})$, at $238 \mathrm{~K}$, mixing time $\left(t_{m}\right)=1 \mathrm{~s}$, at 500 $\mathrm{MHz}\left({ }^{1} \mathrm{H}\right)$. Comparison of ${ }^{1} \mathrm{H}$ horizontal slice extracted from the $2 \mathrm{D}{ }^{1} \mathrm{H}-{ }^{1} \mathrm{H}$ NOESY at $11.65 \mathrm{ppm}$ with the conventional 1D proton spectrum (c, c', red row) and comparison of ${ }^{19} \mathrm{~F}$ vertical slice from the $2 \mathrm{D}{ }^{1} \mathrm{H}-{ }^{19} \mathrm{~F}$ HOESY at 11.65 ppm with the conventional 1D fluorine spectrum (d, d', red column). 

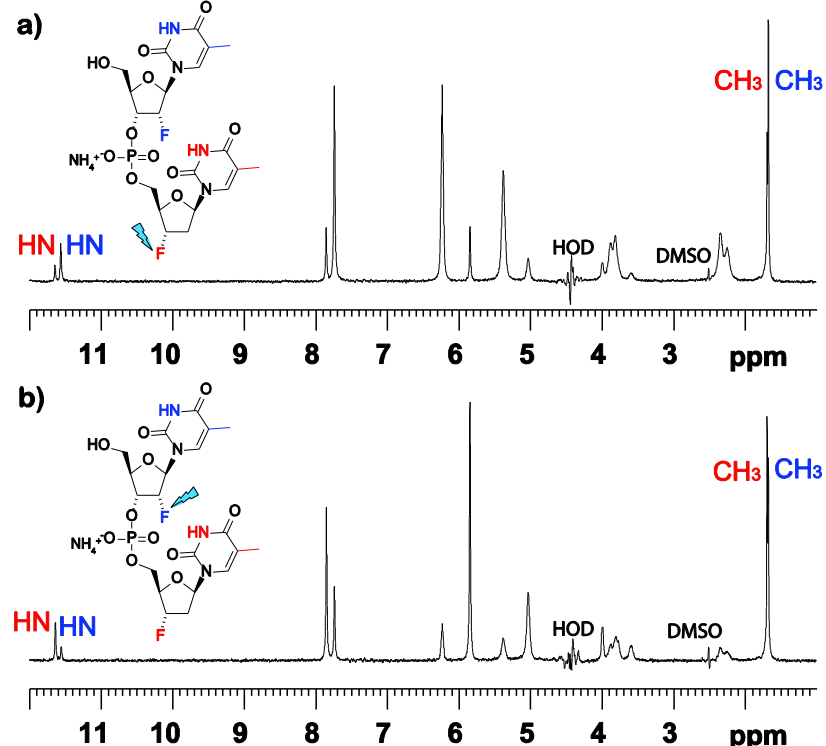

c)

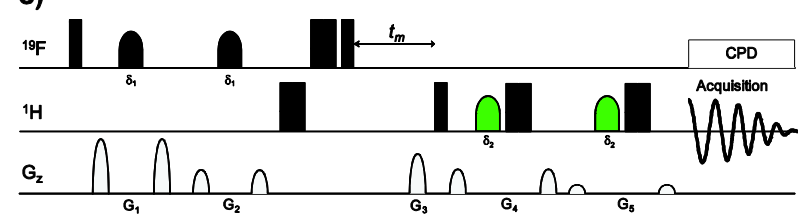

Figure 5. Multiplet selective excitation $1 \mathrm{D}^{1} \mathrm{H}-{ }^{19} \mathrm{~F}$ HOESY spectra of ${ }_{2^{\prime} \mathrm{F}} \mathrm{Tp}_{3^{\prime} \mathrm{FE}} \mathrm{T}$ $(20 \mathrm{mM})$ dissolved in $\left[\mathrm{D}_{6}\right] \mathrm{DMSO} / \mathrm{H}_{2} \mathrm{O}(8: 2, \mathrm{v} / \mathrm{v})(\mathrm{a}, \mathrm{b}, 238 \mathrm{~K}), t_{m}=1 \mathrm{~s}$, at 500 $\mathrm{MHz}\left({ }^{1} \mathrm{H}\right)$. The initial selective inversion pulses excite the fluorine resonance at a) $-172.17 \mathrm{ppm}$ and b) $-200.31 \mathrm{ppm}$. c) Pulse sequence.

\section{Conclusions}

We have demonstrated for the first time that the $\left[\mathrm{D}_{6}\right] \mathrm{DMSO} / \mathrm{H}_{2} \mathrm{O}$ binary solvent turned out to be the easiest to use and most efficient viscous solvent reported so far for the resolution of both polar and moderately apolar components within complex mixtures, taking advantage of NMR spin diffusion. We have pointed out that using $\left[\mathrm{D}_{6}\right] \mathrm{DMSO} / \mathrm{H}_{2} \mathrm{O}$ as viscous binary solvent presents valuable advantages compared to other viscous solvents in terms of NMR sample tube preparation, of choice of the range of analysis temperature and of easy main field locking and shimming.

The component individualization within a Leu-Val, Leu-Tyr, Gly-Tyr and Ala-Tyr mixture in $\left[\mathrm{D}_{6}\right] \mathrm{DMSO} / \mathrm{H}_{2} \mathrm{O}(7: 3, \mathrm{v} / \mathrm{v})$ was achieved at $268 \mathrm{~K}$ by selective $1 \mathrm{D}, 2 \mathrm{D}{ }^{1} \mathrm{H}-{ }^{1} \mathrm{H}$ NOESY and ${ }^{1} \mathrm{H}-{ }^{13} \mathrm{C}$ and ${ }^{1} \mathrm{H}-{ }^{15} \mathrm{~N}$ HSQC experiments. ${ }^{13} \mathrm{C}$ and ${ }^{15} \mathrm{~N}$ nuclei were considered as chemical shift markers that improve the spectrum readability, at the price of a lower sensitivity caused by the low natural abundance of the reporter spins. The heteronuclear NMR spin diffusion approach was also exemplified by ${ }^{19} \mathrm{~F} \mathrm{NMR}$ of compound ${ }_{2{ }^{\prime} \mathrm{aF}} \mathrm{Tp}_{3^{\prime} \mathrm{aF}} \mathrm{T}$ in $\left[\mathrm{D}_{6}\right] \mathrm{DMSO} / \mathrm{H}_{2} \mathrm{O}(8: 2, \mathrm{v} / \mathrm{v})$ at $238 \mathrm{~K}$ by means of 1D selective, 2D ${ }^{1} \mathrm{H}-{ }^{1} \mathrm{H}$ NOESY and ${ }^{1} \mathrm{H}-{ }^{19} \mathrm{~F}$ HOESY experiments.

Future developments will deal the exploration of other viscous solvent blends, with the involvement of other heteronuclei such as ${ }^{31} \mathrm{P}$ and ${ }^{29} \mathrm{Si}$ and with the in-situ monitoring of chemical reactions under spin diffusion conditions.

\section{Experimental Section}

Chemical reagents. $\left[D_{6}\right] \mathrm{DMSO}$ and $\mathrm{D}_{2} \mathrm{O}$ were purchased from Eurisotop (Gif-sur-Yvette, France). Leu-Val, Leu-Tyr, Gly-Tyr and Ala-Tyr were purchased from $\mathrm{TCl}$ Europe (Zwijndrecht, Belgium). All peptides had $95 \%$ or higher purity and were dissolved at a concentration from 10 to 20 $\mathrm{mM}$ in $\left[\mathrm{D}_{6}\right] \mathrm{DMSO} / \mathrm{H}_{2} \mathrm{O} \quad(7: 3, \mathrm{v} / \mathrm{v})$, and $\mathrm{H}_{2} \mathrm{O} / \mathrm{D}_{2} \mathrm{O} \quad(9: 1, \mathrm{v} / \mathrm{v})$. 2'- $\alpha-$ Fluorothymidylyl-(3' , , 5')-3'-deoxy-3'- $\alpha$-fluorothymidine $\left({ }^{\prime}{ }^{\prime} \mathrm{T} \mathrm{Tp}_{3^{\prime} \mathrm{\alpha F}} \mathrm{T}\right)$ was synthetized in the laboratory and was dissolved at a concentration of 20 $\mathrm{mM}$ in $\left[\mathrm{D}_{6}\right] \mathrm{DMSO} / \mathrm{H}_{2} \mathrm{O}(8: 2, \mathrm{v} / \mathrm{v})$.

NMR Spectroscopy. All the NMR experiments on the dipeptide mixture and ${ }_{2}{ }^{\prime} \mathrm{aF} T p_{3^{\prime} \alpha \mathrm{F}} \mathrm{T}$ compound were performed on a:

- Bruker Avance AVIII-500 NMR spectrometer equipped with a $5 \mathrm{~mm}$ $\mathrm{BBFO}+$ probe using the Bruker TOPSPIN Software (Rheinstetten, Germany). Static field gradient pulses were generated by a $10 \mathrm{~A}$ amplifier, so that the sample is submitted to a nominal $0.535 \mathrm{Tm}^{-1}$ gradient. Gradient intensity values are hereafter reported in percent of this value. Gradient pulses were followed by a $200 \mu$ s recovery delay. Temperature was controlled by a Bruker variable temperature (BSVT) unit supplied with chilled air produced by a Bruker cooling unit (BCU-Xtreme).

- Bruker Avance AVIII-600 NMR spectrometer equipped with a $5 \mathrm{~mm} \mathrm{TCl}$ cryoprobe using the Bruker TOPSPIN Software (Rheinstetten, Germany). Static field gradient pulses were generated by a $10 \mathrm{~A}$ amplifier, so that the sample is submitted to a nominal $0.613 \mathrm{Tm}^{-1}$ gradient. Gradient pulses were followed by a $200 \mu$ s recovery delay. Temperature control was performed using a Bruker variable temperature (BVT) unit in combination with a Bruker cooling unit (BCU-05) to provide chilled air.

Dipeptide mixture spectra were calibrated so that the tyrosine $\mathrm{Ha}$ proton and $\mathrm{C} \alpha$ carbon resonances appeared respectively at 7.00 and 132.00 ppm.

${ }_{2}^{2} \mathrm{aF} T \mathrm{~T}_{3^{\prime} \mathrm{aF}} \mathrm{T}$ spectra were calibrated so that the residual proton signal of $\left[\mathrm{D}_{6}\right] \mathrm{DMSO}$ appeared at $2.50 \mathrm{ppm}$.

Additional NMR data acquisition and processing parameters for Figure 1 up to Figure 5 are described in page S-4 to S-5.

\section{Acknowledgements}

Financial support by CNRS, Conseil Regional Champagne Ardenne, Conseil General de la Marne, MESR, Fondation pour la recherche médicale (FDT20130928264) for a Doctoral fellowship to J. Jakhlal and EU-programme FEDER to the PIAneT CPER project is gratefully acknowledged.

Keywords: NMR spectroscopy • Structure elucidation • Spin diffusion $\cdot$ Mixture analysis • Viscous solvent

[1] a) C. Griesinger, G. Otting, K. Wüthrich and R. R. Ernst, J. Am. Chem Soc. 1988, 110, 7870-7872; b) K. F. Morris and C. S. Johnson, J. Am. Chem. Soc. 1992, 114, 3139-3141; c) K. F. Morris and C. S. Johnson, J. Am. Chem. Soc. 1993, 115, 4291-4299; d) K. F. Morris, P. Stilbs and 
C. S. Johnson, Anal. Chem. 1994, 66, 211-215; e) B. T. Doan, B. Gillet, B. Blondel and J. C. Beloeil, J. Magn. Reson. Ser. A 1995, 114, 244 247; f) M. Spraul, A. S. Freund, R. E. Nast, R. S. Withers, W. E. Maas and O. Corcoran, Anal. Chem. 2003, 75, 1546-1551; g) S. Viel, F. Ziarelli and S. Caldarelli, Proc. Natl. Acad. Sci. USA 2003, 100, 96969698; h) M. Godejohann, L.-H. Tseng, U. Braumann, J. Fuchser and M. Spraul, J. Chrom. A 2004, 1058, 191-196; i) G. Pages, C. Delaurent and S. Caldarelli, Angew. Chem. Int. Ed. 2006, 45, 5950-5953; j) G. Pages, C. Delaurent and S. Caldarelli, Anal. Chem. 2006, 78, 561-566; k) S. Caldarelli, Magn. Reson. Chem. 2007, 45, S48-S55; I) M. E. Zielinski and K. F. Morris, Magn. Reson. Chem. 2008, 47, 53-56; m) C. Carrara, S. Viel, F. Ziarelli, G. Excoffier, C. Delaurent and S. Caldarelli, J. Magn. Reson. 2008, 194, 303-306; n) J. C. Hoch, M. W. Maciejewsk and B. Filipovic, J. Magn. Reson. 2008, 193, 317-320; o) J. S. Kavakka V. Parviainen, K. Wähälä, I. Kilpeläinen and S. Heikkinen, Magn Reson. Chem. 2010, 48, 777-781; p) S. V. Kharlamov and S. K. Latypov, Russ. Chem. Rev. 2010, 79, 635; q) A. A. Colbourne, G. A Morris and M. Nilsson, J. Am. Chem. Soc. 2011, 133, 7640-7643; r) C Pemberton, R. Hoffman, A. Aserin and N. Garti, J. Magn. Reson. 2011, 208, 262-269; s) M. Mobli, M. W. Maciejewski, A. D. Schuyler, A. S. Stern and J. C. Hoch, Phys. Chem. Chem. Phys. 2012, 14, 10835 10843; t) N. H. Meyer and K. Zangger, Angew. Chem. Int. Ed. 2013, 52 7143-7146; u) I. Toumi, S. Caldarelli and B. Torrésani, Prog. Nucl. Magn. Reson. Spectrosc. 2014, 81, 37-64; v) K. Kazimierczuk and V. Orekhov, Magn. Reson. Chem. 2015, 53, 921-926; w) K. Zangger Prog. Nucl. Magn. Reson. Spectrosc. 2015, 86-87, 1-20; x) G. D. Poggetto, L. Castañar, G. A. Morris and M. Nilsson, RSC Adv. 2016, 6, 100063-100066.

[2] a) M. P. Williamson and D. H. Williams, J. Chem. Soc., Chem. Commun. 1981, 165-166; b) H. Kovacs, S. Bagley and J. Kowalewski, J. Magn. Reson. 1989, 85, 530-541; c) L. A. Luck and C. R. Landis, Organometallics 1992, 11, 1003-1005; d) C. R. Landis, L. L. Luck and
J. M. Wright, J. Magn. Reson. Ser. B 1995, 109, 44-59; e) S. F. Lienin, R. Brüschweiler and R. R. Ernst, J. Magn. Reson. 1998, 131, 184-190 f) A. J. Simpson, G. Woods and O. Mehrzad, Anal. Chem. 2008, 80 $186-194 ;$ g) M. Zerbetto, A. Polimeno, D. Kotsyubynskyy, L. Ghalebani, J. Kowalewski, E. Meirovitch, U. Olsson and G. Widmalm, J. Chem. Phys. 2009, 131, 234501; h) P. Lameiras, L. Boudesocque, Z Mouloungui, J.-H. Renault, J.-M. Wieruszeski, G. Lippens and J.-M Nuzillard, J. Magn. Reson. 2011, 212, 161-168; i) P. Lameiras and J.M. Nuzillard, Anal. Chem. 2016, 88, 4508-4515.

[3] J. I. Garcia, H. Garcia-Marin and E. Pires, Green Chem. 2014, 16 1007-1033.

[4] C. Moriou, C. Denhez, O. Plashkevych, S. Coantic-Castex, J. Chattopadhyaya, D. Guillaume and P. Clivio, J. Org. Chem. 2015, 80, 615-619.

[5] a) J. Catalán, C. Díaz and F. García-Blanco, J. Org. Chem. 2001, 66, 5846-5852; b) M. M. Palaiologou, I. E. Molinou and N. G. Tsierkezos, J. Chem. Eng. Data 2002, 47, 1285-1289.

[6] a) R. N. Havemeyer, J. Pharm. Sci. 1966, 55, 851-853; b) I. Płowaś, J. Świergiel and J. Jadżyn, J. Chem. Eng. Data 2013, 58, 1741-1746; c) Y.-C. Wen, H.-C. Kuo, J.-L. Guo and H.-W. Jia, J. Phys. Chem. B 2016 $120,13125-13135$

[7] T. L. Hwang and A. J. Shaka, J. Magn. Reson. Ser. A 1995, 112, $275-$ 279.

[8] K. Wüthrich, NMR of proteins and nucleic acids 1986, New York: Wiley.

[9] K. Stott, J. Keeler, Q. N. Van and A. J. Shaka, J. Magn. Reson. 1997 125, 302-324.

[10] K. Stott, J. Stonehouse, J. Keeler, T.-L. Hwang and A. J. Shaka, J. Am. Chem. Soc. 1995, 117, 4199-4200.

[11] a) C. Dalvit and A. Vulpetti, Magn. Reson. Chem. 2012, 50, 592-597; b) A. Vulpetti and C. Dalvit, ChemMedChem 2013, 8, 2057-2069. 
Entry for the Table of Contents (Please choose one layout)

Layout 1:

\section{FULL PAPER}

Composite DMSO-water viscous solvents was used for the first time to access the individual NMR spectra of mixture components in spin diffusion conditions. The involvement of heteronuclei such as ${ }^{19} \mathrm{~F},{ }^{15} \mathrm{~N}$ and ${ }^{13} \mathrm{C}$ facilitated spectral interpretation.

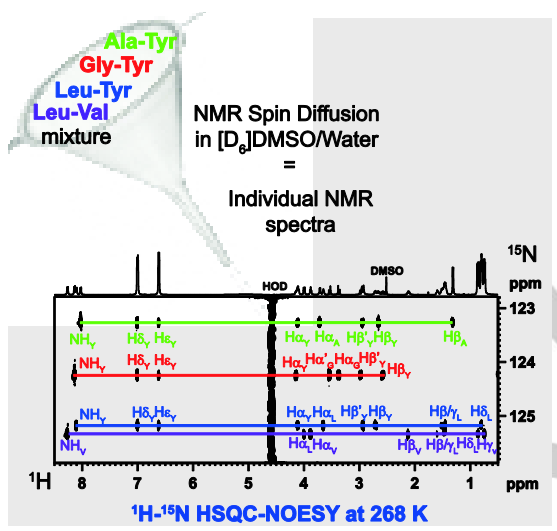

Pedro Lameiras*, Solène Patis, Jouda Jakhlal, Stéphanie Castex, Pascale Clivio and Jean-Marc Nuzillard*

Page No. - Page No.

Small molecule mixture analysis by heteronuclear NMR under spin diffusion conditions in the viscous DMSO-water solvent 